\title{
Effectiveness of Fungal Bacterial Interactions as Biofilmed Biofertilizers on Enhancement of Root Growth of Hevea Seedlings
}

\author{
R. P. Hettiarachchi ${ }^{1, \#, ~ R . ~ S . ~ D h a r m a k e e r t h i ~}{ }^{3}$, A. N. Jayakody ${ }^{3}$, \\ G. Seneviratne ${ }^{2}$, E. de Silva ${ }^{1}$, T. Gunathilake ${ }^{1}$ and A. Thewarapperuma ${ }^{1}$ \\ ${ }^{1}$ Rubber Research Institute of Sri Lanka, Dartonfield, Agalawatta \\ ${ }^{2}$ Institute of Fundamental Studies, Hantana Road, Kandy \\ ${ }^{3}$ University of Peradeniya, Peradeniya \\ \# Corresponding Author: \\ E-mail: rasikarri@yahoo.com
}

\begin{abstract}
This study examined the influence of biofilmed biofertilizers (BFBFs) on the root growth of Hevea seedling under greenhouse conditions. Morphologically different bacteria and fungi were isolated from rubber root rhizosphere and investigate their efficiency of biofilm formation. Prepared biofilm biofertilizer was applied with different rates of chemical fertilizers. Growth promoting effect of BFBFs coinoculation was evaluated with rubber seedlings growing in microcosms. Root growth was evaluated at the end of the experiment. It was observed that, BFBFs application as compared to inorganic fertilizer application only treatment increased root growth of the seedling rubber plants. The response of BFBFs was more pronounced than that of full recommended inorganic fertilizer application. These findings contribute to the understanding of the interplay between BFBFs and rubber seedlings at nursery stage. Importantly, co-inoculation with BFBFs at nursery stage could be effective biofertilization strategy for rubber seedling production.
\end{abstract}

KEYWORDS: Biofilmed biofertilizer, Hevea brasiliensis, Rhizosphere microorganisms, Root growth

\section{Introduction}

Rubber plantations were first established in Sri Lanka at the beginning of the $20^{\text {th }}$ century. Since then many individual plantations have under grown 3 or 4 planting cycles. Depleted soil nutrients must be replenished through balanced and efficient use of organic and inorganic fertilizers and through improved soil management practices.

Among the organic nutrient sources, bio fertilizers have been recognized as economical alternatives for imported fertilizers, because they are less bulky 
compared to organic fertilizers. Considerable attention has been focused recently on microbial interference on biofilm formation in the environment and their potential to increase nutrient availabilities in the soils. A biofilm consists of microbial cells (algal, fungal, bacterial and / or other microbial) and an extra cellular biopolymer. These cells produce exo-polysaccharide, (EPS) which provide structure and protection to the community (Seneviratne, 2003).

Biofilms attached to the plant roots of some crops help to cycle nutrients as well as biocontrol of pests and diseases, resulting in increased agricultural productivity (Seneviratne, 2003). Plant growth-promoting bacteria are thought to form biofilms on roots (Seneviratne et al., 2008b). The conventional practice of plant inoculation with monocultures or mixed cultures of effective microbes may not give the highest microbial effect, which may only be achieved by biofilm formation. Moreover, plant growth hormones, such as IAA produced by the biofilm (Bandara et al., 2006), increased the growth of roots. Study showed that a biofilm with nitrogenase activity has improved $\mathrm{N}_{2}$ fixing symbiosis of Soybean compared to a conventional rhizobial inoculants (Jayasinghearachchi and Seneviratne, 2004).

Also fungal-rhizobial biofilms could be used more effectively in biosolubilizing poorly soluble ERP (Seneviratne and Jayasinghearachchi, 2005). The usefulness of biofertilizers has already been established in soybean and mung bean cultivation in Sri Lanka (Seneviratne and Jayasinghearachchi, 2005). The plant growth promoting effects of biofilmed biofertilizers (BBFs) were evaluated using rice, tea, wheat, and anthurium (Seneviratne et al., 2009).

Several studies indicated so far that the biofilmed biofertilizers gave encouraging results on soil fertility (Seneviratne et al., 2008a; Seneviratne et al., 2008b; Seneviratne et al., 2009 and Seneviratne et al., 2011). The objective of the present study was to isolate the soil born fungi and bacteria in rubber roots and they were screened in-vitro to identify efficient biofilms and was evaluated their efficiency for the root growth enhancement of Hevea seedlings.

\section{Materials and Methods}

\section{Collection of Root Samples}

Three rubber growing fields with Agalawatta series soils but with different fertilizer application history, i.e. no organic or chemical fertilizers added, only organic manures added and only chemical fertilizers added, were selected to isolate rhizosphere micro-organisms for this study. Root samples were taken around the tree from three to four places with in $1 \mathrm{~m}$ radius from the base of the plant. Samples were placed in polythene bags with several holes to keep those samples under aerobic conditions and brought to the laboratory at the Rubber Research Institute of Sri Lanka (RRISL). 


\section{Isolation of Rhizosphere Micro-Organisms}

Roots collected from all sites were placed on potato dextrose agar (PDA) (Difco) and nutrient agar (NA) (Difco) plates for the isolation of rhizosphere fungi and bacteria respectively (Parkinson et al., 1971).

\section{Isolation of Bacterial Strains}

Root samples were shaken in $50 \mathrm{ml}$ sterilized distilled water for $30 \mathrm{~min}$ to extract rhizosphere bacteria. Samples were then serially diluted in sterilized distilled water and suspensions spread, in duplicate, on NA plates. Cultures were incubated at $25^{\circ} \mathrm{C}$ for 24 to 48 hours and, on the basis of pigment, shape, size, surface texture and opacity, morphologically distinct colonies of bacteria were isolated by transfer of single colonies to the NA medium from which they were obtained. Isolates were examined for purity by microscopy.

\section{Isolation of Fungi}

Root samples transferred to Petri-dishes containing PDA were used for the isolation of fungi. Placed the root sample on PDA medium and incubate at $25^{\circ} \mathrm{C}$ for 3 to 5 days. Observed for growth of fungi originated from the root samples and mark their growing tips on the underside of the petri dish.

\section{Purification of Fungi}

Transferred a small bit of agar medium containing fungal growth to the centre of petri dishes containing PDA medium, using a flame sterilized inoculation needle and incubate at room temperature for few days. More than 10fungal species were isolated depending on the variability of the cultural and reproductive morphology. Resulting colonies were purified on PDA plates and identified using standard mycological keys. Selected nonpathogenic fungal colonies were stored on PDA slopes at $4^{0} \mathrm{C}$ until further use.

\section{Formation of Biofilm}

Biofilm was prepared according to the method developed by Seneviratne et al., 2011.

\section{Green House Experiment}

Soil columns were prepared using $130 \mathrm{~cm}$ long PVC pipes of $11 \mathrm{~cm}$ diameter. One end was covered with a mesh and polyester cloth to prevent soil removal during experimental period. Soil was air dried; stubble and root particles were removed by hand and crushed gently to pass through $2 \mathrm{~mm}$ sieve. In each treatment, $4 \mathrm{Kg}$ of soil was thoroughly mixed with $50 \mathrm{~g}$ of compost and $50 \mathrm{~g}$ of high grade ERP (HERP) before filling the columns. One germinated seed was planted in each column. Tap 
water was added to bring the soil to $80 \%$ of its water holding capacity and the water content was checked weekly, by weighing columns and then the original water content was restored. One month after planting treatments was initiated. The RRISL recommended NPKMg mixture was applied at zero, half and full of the currently recommended level with or without the application of developed BFBFs. This resulted in 6 treatment combinations. NPKMg fertilizers were applied at monthly intervals while freshly prepared BFBFs was applied at biweekly intervals.

The treatments were arranged in a randomized complete block design with 10 single plants as replicates.

\section{Growth Assessments}

At the end of the experimental period, root weight was measured separately. Carefully remove the soil column from the PVC pipe and observed their root growth pattern. Each of the root systems was separated into feeder root and tap root and finally their dry weights were recorded by drying the components at $105{ }^{\circ} \mathrm{C}$ in an oven for constant weight.

\section{Statistical Analysis}

Statistical analysis of the experimental data was done by analysis of variance followed by a mean separation procedure, Duncan's Multiple Range test (DMRT), at a probability level of 0.05 .

\section{Results}

\section{Diversity of Bacterial Isolates}

Diversity in morphology was observed. Morphologically distinct ten bacterial isolates were selected for further studies.

\section{Variability in Cultural Morphology}

Bacterial isolates showed variations in colony size, shape, margin, elevation, appearance, pigmentation and optical property. It was also observed that there was no variation in surface texture and very little variation in margin, appearance and optical property among the isolates (Table 1). There is a significant variation in shape of colony on solid medium. Most of colonies were circular and others were spindle, irregular and filamentous in shape. We observed that some bacteria isolates could secrete much extracellular polysaccharides in the medium. Bacterial cells B2, B4, B6, B7, B9 and B10 produce sticky exopolysaccharide layer around their cells. While the size of the isolates varied within the range of $25-60 \mu \mathrm{m}$. 
Table 1: Variability in cultural morphology produced by different bacterial isolates.

\begin{tabular}{cccccccc}
\hline $\begin{array}{c}\text { Bacterial } \\
\text { No. }\end{array}$ & Shape & Margin & Elevation & $\begin{array}{c}\text { Surface } \\
\text { Texture }\end{array}$ & Appearance & Pigmentation & $\begin{array}{c}\text { Optical } \\
\text { Property }\end{array}$ \\
\hline $\mathrm{B}_{1}$ & Circular & Entire & Umbonate & Smooth & Glistening & Yellow & Transparent \\
$\mathrm{B}_{2}$ & Irregular & Entire & Convex & Smooth & Glistening & Pale Yellow & Opaque \\
$\mathrm{B}_{3}$ & Irregular & Entire & Pulvinate & Smooth & Glistening & Cream & Opaque \\
$\mathrm{B}_{4}$ & Irregular & Undulate & Convex & Smooth & Glistening & Yellow & Translucent \\
$\mathrm{B}_{5}$ & Circular & Entire & Raised & Smooth & Dull & White & Opaque \\
$\mathrm{B}_{6}$ & Circular & Entire & Convex & Smooth & Dull & Cream & Opaque \\
$\mathrm{B}_{7}$ & Spindle & Undulate & Convex & Smooth & Glistening & White & Opaque \\
$\mathrm{B}_{8}$ & Circular & Entire & Convex & Smooth & Glistening & Yellow & Opaque \\
$\mathrm{B}_{9 / 12}$ & Filamentous & Entire & Raised & Smooth & Dull & White & Opaque \\
$\mathrm{B}_{10 / 25}$ & Spindle & Undulate & Flat & Smooth & Glistening & White & Translucent \\
\hline
\end{tabular}

\section{Variability in Colony Morphology of Bacterial Isolates}

Significant variations were observed in the colony morphology among the different isolates (Figure 1). Differences were mainly observed in the shape, margin, pigmentation and optical property. Bacteria with different shapes present different physical features to the outside world, and these features help cells cope with and adapt to external conditions (Young, 2007).

Considering their morphology most of the bacterial strains were very close to Bacillus spp. It was reported that Bacillus spp. are abundant and widely distributed in rubber growing soils.

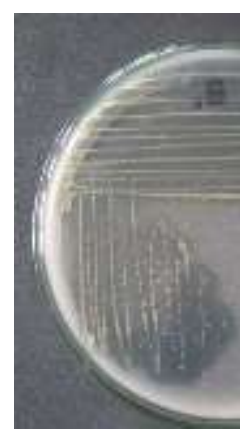

B1-front view

B1 - Single colony

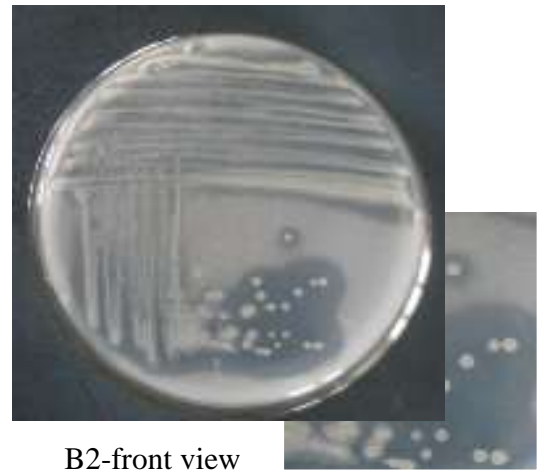

B2-Single colony 
Journal of Environmental Professionals Sri Lanka: 2014 - Vol. 3 - No. 2

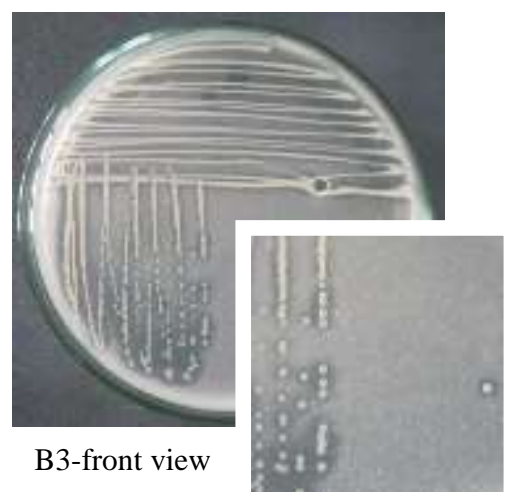

B3 - Single colony

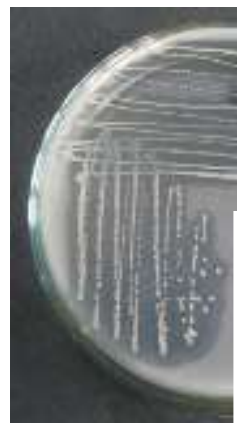

B5-front view

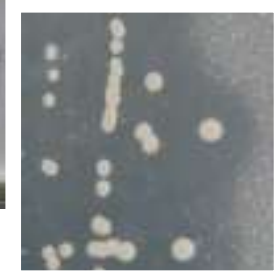

B5-Single colony

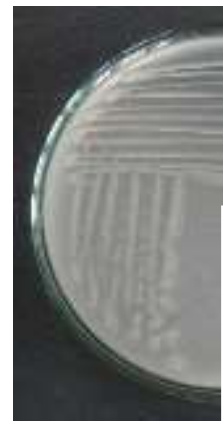

B7-front view

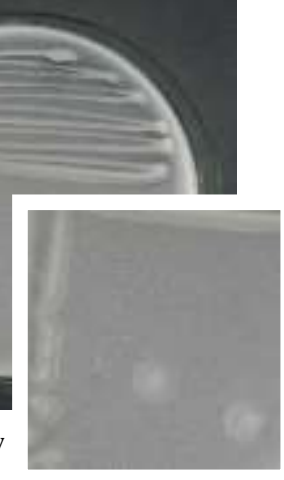

B7-Single colony

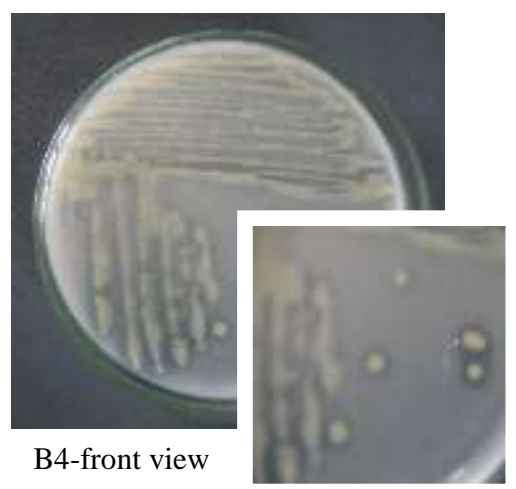

B4 - Single colony

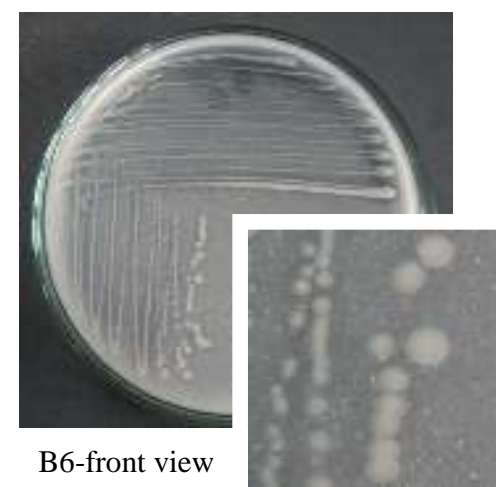

B6-Single colony

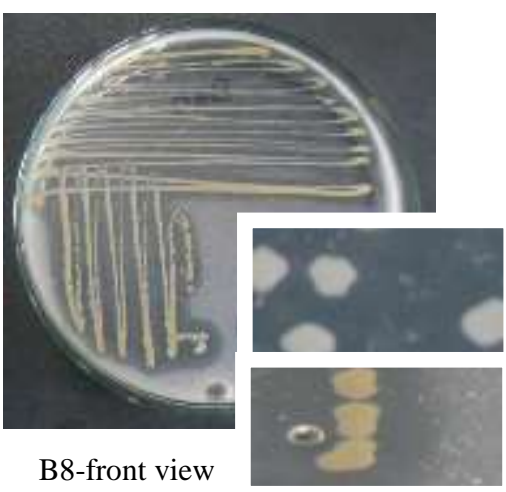

B8-Single colony 


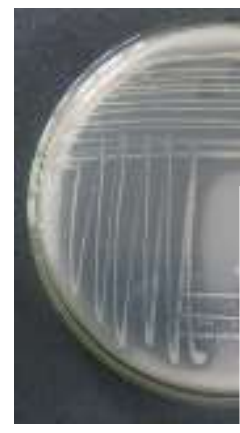

B9-front view

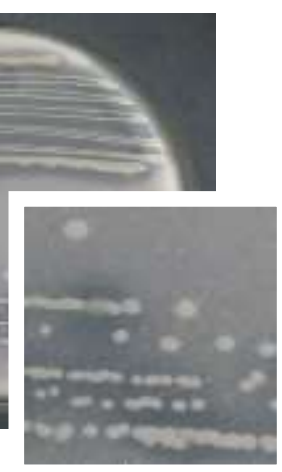

B9-Single colony

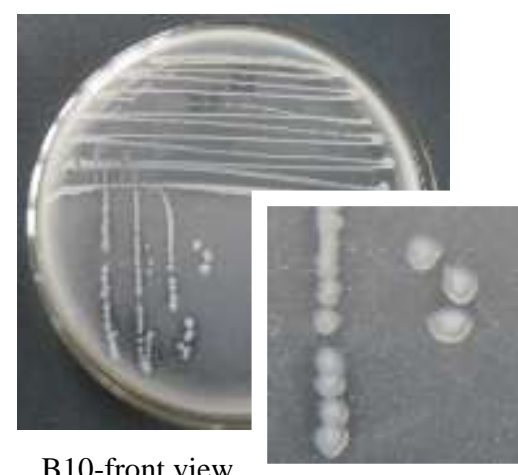

B10-Single colony

Figure 1: Variability in colony morphology produced by different bacterial isolates

\section{Diversity of Fungal Isolates}

Several isolates of fungi were obtained from different fertilizer application histories. All isolates were purified and single conidia cultures were raised on potato dextrose agar (PDA) at room temperature (RT) $\left(28 \pm 2^{\circ} \mathrm{C}\right)$. Based on an initial assessment of colony morphology, the most common three isolates listed in Table 2 were selected for further studies.

\section{Variability in Cultural Morphology and Colony Morphology}

Fungal isolates showed variation in colony color and texture. The isolate F1 was mouse green on top/whitish green on lower surface, F2, was bright yellow to dark green on top/off white on lower surface, F4 was white colony with green shade on top/green color on lower surface (Table 2 and Figure 2).

Table 2: Variation in cultural morphology among different fungal isolates from rubber growing soils

\begin{tabular}{ccccc}
\hline $\begin{array}{c}\text { Isolate } \\
\text { No. }\end{array}$ & \multicolumn{2}{c}{ Colony Colour } & Texture & Margin \\
\cline { 2 - 4 } F1 & Mouse green & Whitish green & $\begin{array}{c}\text { Flat colonies with } \\
\text { raised conidia } \\
\text { heads }\end{array}$ & Even \\
\hline F2 & $\begin{array}{c}\text { Yellowish } \\
\text { brown }\end{array}$ & $\begin{array}{c}\text { Off white color } \\
\text { with green } \\
\text { shades }\end{array}$ & $\begin{array}{c}\text { Flat mycelium } \\
\text { growth }\end{array}$ & Even \\
\hline F4 & $\begin{array}{c}\text { White colony } \\
\text { with green } \\
\text { shade }\end{array}$ & Green & $\begin{array}{c}\text { Flat colony spread } \\
\text { all over the plate }\end{array}$ & Even \\
\hline
\end{tabular}




\section{Variability in Colony Morphology of Different Isolates}

Significant variations were observed in the cultural morphology among the different isolates (Figure 2). Differences were observed in colony colour and texture.

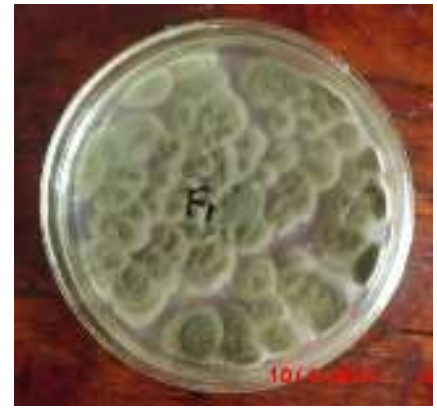

F1

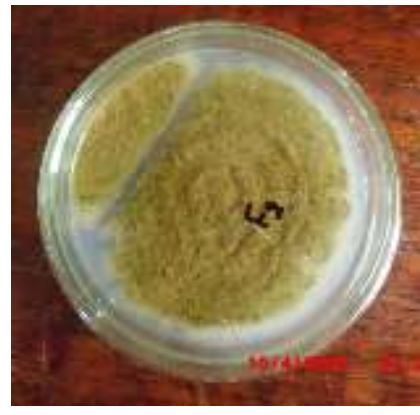

F2

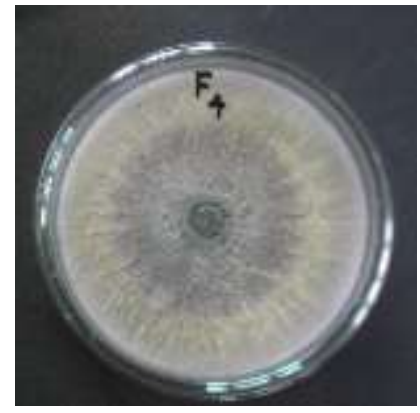

F4

Figure 2: The colonies (upper surface) of the three different isolates as on PDA after incubation for 10 days at RT

\section{Identification of Fungus}

These fungal strains were identified using CMI description and Royal Horticultural Society (RHS) mini color chart to record the colony characteristics. Among the culture collection, F1 isolate was identified as Penicillium species, F2 isolate was identifies as Aspergillus species and F4 was identified as Trichoderma spp,.Aspergillus spp, and Penicillium spp were present the most abundant genus in the rubber growing soils and Trichoderma spp.was the next most common gene. However, except pathogenic fungal isolates the most common Aspergillus spp, Trichoderma spp, Penicillium spp were selected for further studies. Isolate No. and fungal genes were shown in Table 3.

Table 3: Isolate numbers and their identifications

\begin{tabular}{cc}
\hline Isolate No. & Identification \\
\hline F1 & Penicillium spp. \\
\hline F2 & Aspergillus spp. \\
\hline F4 & Trichoderma spp. \\
\hline
\end{tabular}

\section{Biofilm Formation}

Bacterial isolates B2, B5 and B10 had an ability to form biofilm with fungi. B10 bacteria was formed biofilm properly with fungi Aspergillus spp. (F2) but less extent with Trichoderma spp. (F4) and no biofilm formation with Penicillium spp. (F1). Tow bacterial isolates B2 and B5 with fungi Aspergillus (F2) and only B5 bacterial isolate with Trichoderma spp. (F4) showed marginal biofilm production. Significant variations were observed in the formation of biofilm among the different isolates (Table 4). 
Table 4: Observation of biofilm formation - colonization of bacteria on fungi spp.

\begin{tabular}{cccc}
\hline Bacterial No. & $\begin{array}{c}\text { Penicillium spp. } \\
\text { (F1) }\end{array}$ & $\begin{array}{c}\text { Aspergillus spp. } \\
\text { (F2) }\end{array}$ & $\begin{array}{c}\text { Trichoderma } \text { spp. } \\
\text { (F4) }\end{array}$ \\
\hline B1 & No & No & No \\
\hline B2 & No & $25 \%$ & No \\
\hline B3 & No & No & No \\
\hline B4 & No & No & No \\
\hline B5 & No & $50 \%$ & $5 \%$ \\
\hline B6 & No & No & No \\
\hline B7 & No & No & No \\
\hline B8 & No & No & No \\
\hline B9 & No & No & No \\
\hline B10 & No & $100 \%$ & $25 \%$ \\
\hline & & &
\end{tabular}

\section{Total Root Dry Matter Production}

Total root dry matter production of the plants was measured at the end of the experiment is given in Figure 3. Considering zero, half and full recommended inorganic fertilizer only application treatments (T1, T2, T3), fertilizer application was inversely correlated with root growth (Figure 3). Significantly the highest root growth was observed with no inorganic fertilizer treatment (T1), and increased inorganic fertilizer from half (T2) to full (T3) of the recommended fertilizer level was observed reduction of root growth. Biofilm biofertilizeronly treatment (T4) gave slightly higher root growth than the recommended fertilizer level (T3).

Combine use of BFBFs with inorganic fertilizer from half (T5) to full (T6) of the recommended fertilizer level treatments greatly influenced root growth than their non BFBFs application treatments (T2 and T3). The treatments having combined use of half recommended inorganic fertilizer with BFBFs (T5) and full recommended inorganic fertilizer with BFBFs (T6) gave significantly higher root growth compared to full recommended inorganic fertilizer treatment (T3).

\section{Root Growth Promotion}

The maximum and significantly high root growth was observed with no fertilizer application treatments (T1\&T4). Results showed in figure 4 and 5, the combine use of inorganic fertilizer with BFBFs treatments (T5 \& T6) gave significantly higher root growth than their comparative inorganic fertilizers only treatments (T2 \& T3). 


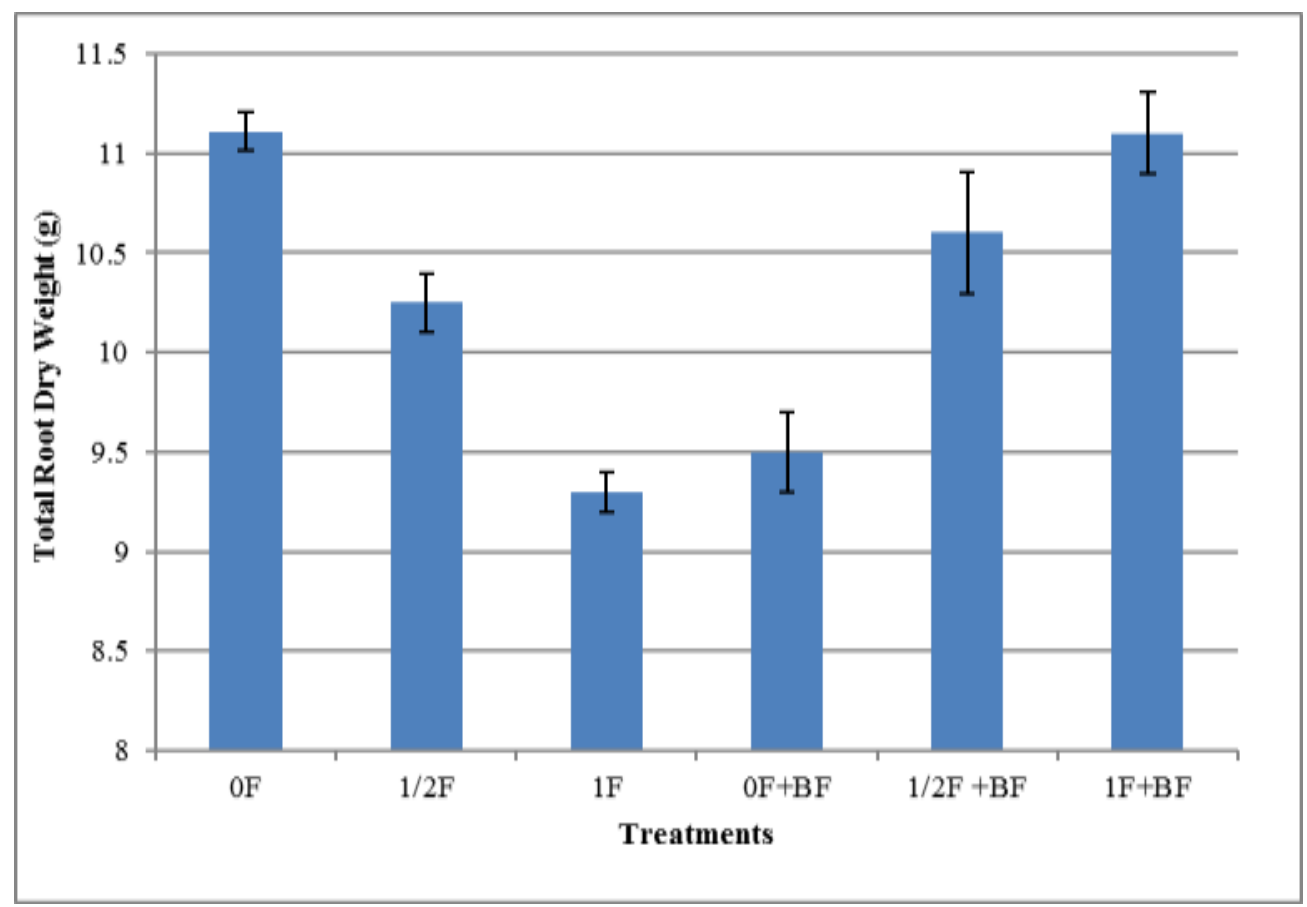

Figure 3: Effect of different fertilizer applications on total root dry matter of Rubber plants

$\mathrm{OF} \quad=$ Not any fertilizer

$1 / 2 \mathrm{~F} \quad=$ Half of the recommended inorganic fertilizer

$1 \mathrm{~F}=$ Full of the recommended inorganic fertilizer

BFBFs $\quad=$ Biofilmed biofertilizers only

$1 / 2 \mathrm{~F}+\mathrm{BFBFs}=$ Half of the recommended inorganic fertilizer + BFBFs

$1 \mathrm{~F}+\mathrm{BFBFs}=$ Full of the recommended inorganic fertilizer + BFBFs 

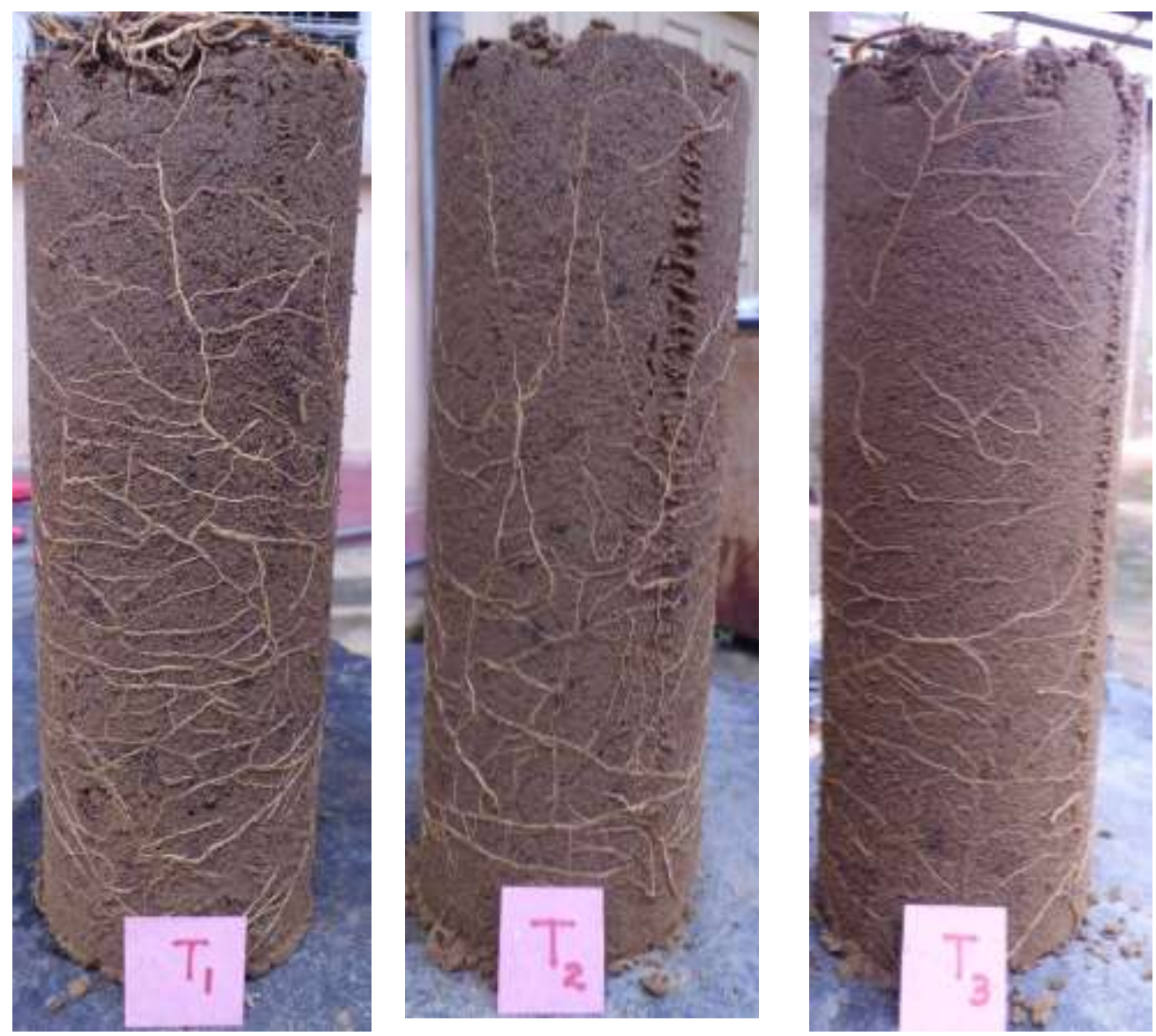

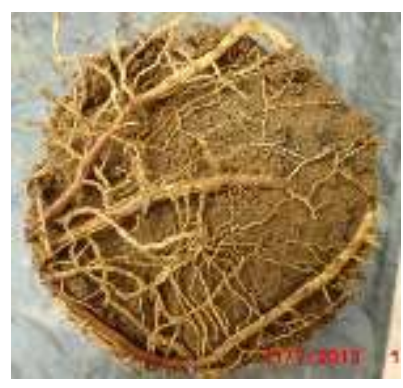

$\mathrm{OF}$

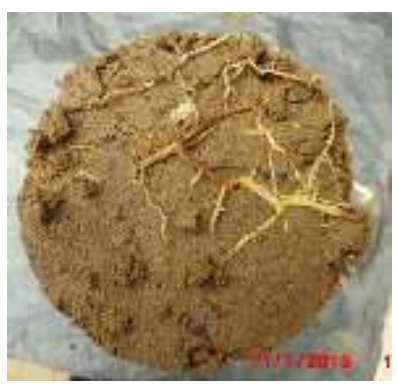

$1 / 2 \mathrm{~F}$

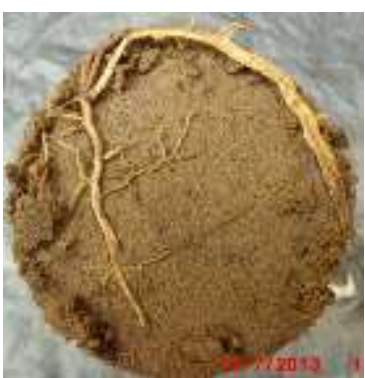

1F

Figure 4: Side view of the root growth and their growth at the bottom of the soil column 

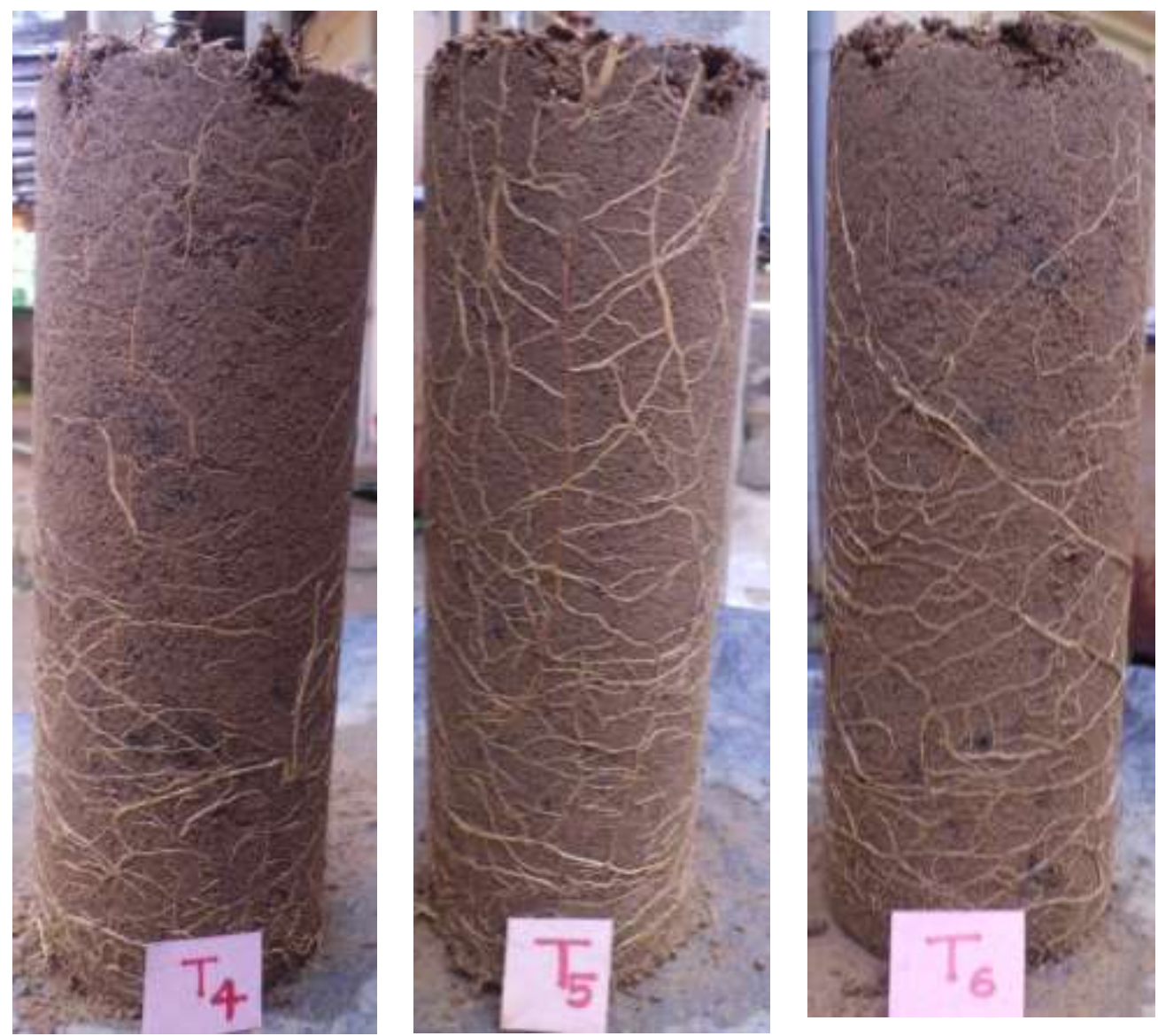

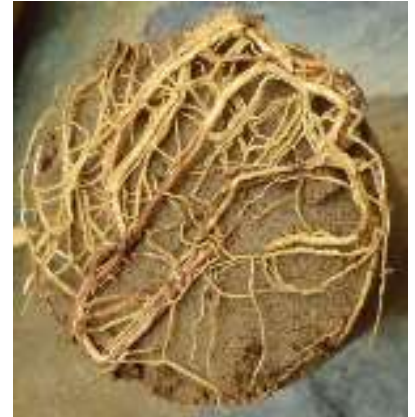

BF

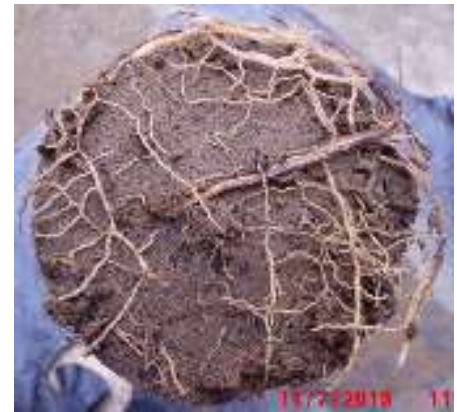

$\mathrm{BF}+1 / 2 \mathrm{~F}$

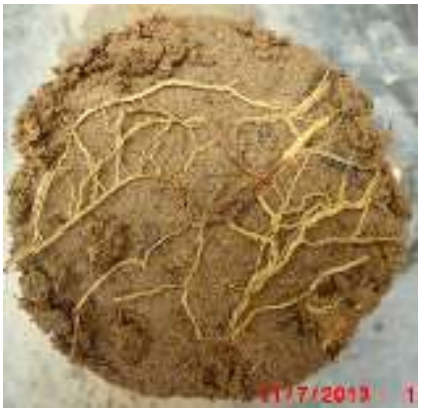

$\mathrm{BF}+1 \mathrm{~F}$

Figure 5: Side view of the root growth and their growth at the bottom of the soil column 


\section{Discussion}

Since then many individual rubber plantations have undergone around four to five planting cycles since their first establishment. The continuous cultivations of monocultural cropping system lower fertility and productivity of soils due to deterioration of physical, chemical and biological properties as a result of soil erosion, nutrient removal by crop and timber during replanting (Punyalal et al., 1992; Balasubramanian and Nnadi, 1980; Kang and Wilson, 1987). Low soil fertility is considered as one of the most important constrains on improved agricultural production. Depleted soil cannot sustain economic yield even with large doses of inorganic fertilizers. It must be replenished through balance and efficient use of organic and inorganic sources and improved soil management practices.

Soil microorganisms are of critical importance in nutrient cycling processes, and also they are involved in various biotic activities of the soil ecosystem to make it dynamic for nutrient turn over and sustainable for crop production (Ahemad et al., 2009 and Chandler et al., 2008). They stimulate plant growth through mobilizing nutrients in soils, producing numerous plant growth regulators, enhance resistance to stress, stabilize soil aggregates, and improve soil structure and organic matter content (Ahemad, 2012; Ahemad and Malik, 2011; Hayat et al., 2010; Rajkumar et al., 2010 and Braud et al., 2009). Indeed, the bacteria lodging around/in the plant roots (rhizobacteria) are more versatile in transforming, mobilizing, solubilizing the nutrients compared to those from bulk soils (Hayat et al., 2010). Therefore, the rhizobacteria are the dominant deriving forces in recycling the soil nutrients and consequently, they are crucial for soil fertility (Glick, 1999).

Bacteria are the most prominent among the soil microbes usually more numerous than the others (Alexander, 1977). Bacterial isolates were the predominant microbe and then fungi represent the second populated microoganismin rubber root rhizozphere of this present study. Most of the bacterial isolates had an ability to secrete exopolysaccharides. This exopolysaccharide (EPS) is produced by bacteria in the rhizosphere (Costerton et al., 1995), is not only provide many advantages to bacterial cells, it also enhance soil aggregation, which in turn improves water stability, which is critical to the survival of the plant specially under soil moisture stress conditions. Fungi are also an importantbiological factor in the soil. Among the identified fungi, Aspergillus spp., Penicillium spp. and Trichoderma spp. were common. Microbiological studies with plant roots favour nutrient uptake, information on microbiological association in rubber is rather limited (Wastie, 1965; Jayaratne, 1982; Jayasinghe et al., 1984; Jayasinghe et al., 1989).

In this study, we monitored the interactions between the isolated bacteria and fungi based on morphological growth and adherence. We found that three bacterial isolates grew and adhered on the surface of fungi (Table 4). The growth rates and patterns were, however, different between isolates. For example, B2 was rarely detected and grew very slowly. In contrast, B5grew quickly and strongly adhered on the mycelial surface. While, B10 shows significant growth, and adherence properly 
on the mycelia of Aspergillus. It was fast growing and formed a dense colony around mycelia after only 24 hours incubation. Several studies conducted so far with the BFBFs under laboratory, nursery and field conditions for tea in Sri Lanka have shown positive results for soil fertility and crop growth (Seneviratne et al., 2009 and Seneviratne et al., 2011).

All those enhanced performances of the BFBFs application over chemical fertilizers alone may be due to the persistence of biofilms (Seneviratne et al., 2008a; Seneviratne et al., 2008b). The conventional application of plant inoculation with monocultures or mixed cultures of effective microbes may not give the highest microbial effect, which may only be achieved by biofilm formation (Bandara et al., 2006). Observations made on root growth in the present study using rubber seedlings also support the observations made in previous studies for other crops. The combined use of chemical fertilizer with BFBFs treatments recorded higher values than their chemical fertilizer alone treatments (Figure 3 and 4) in rubber seedling plants. In the absence of chemical fertilizer, the highest density of roots was observed, which was comparable to that of $1 / 2 \mathrm{~F}+\mathrm{BFBFs}$ and $1 \mathrm{~F}+\mathrm{BFBFs}$ (Figure 3).

Also it was noted that, no inorganic fertilizer treatment $(0 \mathrm{~F})$, half recommended inorganic fertilizer with BFBFs $(1 / 2 \mathrm{~F}+\mathrm{BFBFs})$ and full recommended fertilizer with BFBFs $(1 \mathrm{~F}+\mathrm{BFBFs})$ gave the highest root growth then the recommended fertilizer alone treatment (1F). Positive responses such as plant growth hormone production, mineral nutrients solubilization in the soil and biocontroling effects could have contributed to the increased plant growth with BFBFs. Understanding the interactions between bacteria and fungi and their biodiversity will advance our knowledge on microbial ecology in rubber growing soils and therefore could have the potential to sustain modern agriculture systems with the use of microbial community of biofilm as biofilmed biofertilizers.

\section{References}

Ahemad, M. (2012). "Implications of bacterial resistance against heavy metals in bioremediation: A review". The IIOAB Journal. 3: 39-46.

Ahemad, M. and A. Malik (2011). "Bioaccumulation of heavy metals by zinc resistant bacteria isolated from agricultural soils irrigated with wastewater". Bacteriol. J. 2: $12-21$.

Ahemad, M., M. S. Khan, A. Zaidi and P. A. Wani (2009). "Remediation of herbicides contaminated soil using microbes". In: Microbes in sustainable agriculture. Khan, M. S., A. Zaidi and J. Musarrat (Eds.). Nova Science Publishers, New York, USA.

Alexander, M. (1977). "Mineralization and immobilization of nitrogen”. In: Introduction to soil microbiology. JohnWiley \& Sons, NewYork (2 ${ }^{\text {nd }}$ Ed.), 136-247. 
Balasubramanian, V. and L. A. Nnadi (1980). "Crop residue management and soil productivity in Savanna areas of Nigeria". FAO Soil Bulletin, 43: 106-120.

Bandara, W. M. M. S., G. Seneviratne and S. A. Kulasooriya (2006). "Interactions among endophytic bacteria andfungi: effects and potentials". J. Biosci. 31: 645-650.

Braud, A., K. Jézéquel, S. Bazot and T. Lebeaum (2009). "Enhanced phytoextraction of an agricultural $\mathrm{Cr}-, \mathrm{Hg}$ - and $\mathrm{Pb}$-contaminated soil by bio augmentation with siderophore producing bacteria". Chemosphere. 74: 280-286.

Chandler, D., G. Davidson, W. P. Grant, J. Greaves and G. M. Tatchell (2008). "Microbial bio pesticides for integrated crop management: an assessment of environmental and regulatory sustainability". Trends Food Sci. Tech. 19: 275-283.

Costerton, J. W., Z. Lewandowski, D. E. Caldwell, D. R. Korber and H. M. Lappin-Scott (1995). "Microbial biofilm". Annu Rew Microbiol. 49: 711-745.

Glick, B. R., C. L. Patten, G. Holguin and G. M. Penrose (1999). "Biochemical and genetic mechanisms used by plant growth promoting bacteria". Imperial College Press, London.

Hayat, R., S. Ali, U. Amara, R. Khalid and I. Ahmed (2010). "Soil beneficial bacteria and their role in plant growth promotion: A review". Ann Microbiol. 60: 579-598.

Jayaratne, A. H. R. (1982). "Endomycorrhiz as of rubber growing soils of Sri Lanka". Journal of the Rubber Research Institute of SriLanka, 60: 47-57.

Jayasinghe, C. K., C. A. Parker, D. K. Kidhy and S. A. Kulasooriya (1984). "Nodulation of Pueraria phaseoloides by introduced rhizobia in competition with neutralized strains in three different soils". Proceeding of the International Rubber Conference, Rubber Research Institute of SriLanka. 1(2): 563-568.

Jayasinghe, C. K., C. A. Parker and S. A. Kulasooriya (1989). "Nodulation, nitrogenase activity and major nutrient constituents of common cover legumes during early growth". Journal of the Rubber Research Institute of Sri Lanka, 69: 27-35.

Jayasinghearachchi, H. S. and G. Seneviratne (2004). "Can mushrooms fix atmospheric nitrogen". J. Biosci. 23: 293-296.

Kang, B.T. and G. F. Wilson (1987). "The development of alley cropping as a promising agro forestry technology". In: Agro forestry: A decade of development. Steppler, H. A. and P. K. R. Nair (Ed.). ICRAF, Nairobi, Kenya.

Parkinson, D., T. R. G. Gray and S. T. Williams (1971). "Isolation of microorganism”. In: Methods for studying the ecology of microorganisms. IBP Handbook. 19: 36-55.

Punyalal, M. G., P. Abeygunawardena and P. T. Bandara (1992). "Economic feasibility of using organic mulching materials in cowpea and maize cultivation in the dry zone of Sri Lanka”. Tropical Agricultural research. 4: 196-208. 
Rajkumar, M., N. Ae, M. N. V. Prasad and H. Freitas (2010). "Potential of siderophoreproducing bacteria for improving heavy metal phytoextraction". Trends Biotechnol. 28: $142-149$.

Seneviratne, G. (2003). "Development of eco-friendly beneficial microbial biofilms". Curr. Sci. 85: 1395-1396.

Seneviratne, G. and H. S. Jayasinghearachchi (2005). "A rhizobial biofilm with nitrogenase activity alters nutrient availability in soil”. Soil Biol. Biochem. 37: 1975-1978.

Seneviratne, G., M. L. Keeskes and I. R. Kennedy (2008a). "Biofilmed biofertilizers: novel inoculants for efficient use in plants". In: Efficient nutrient use in rice production in Vietnam achieved using inoculant as biofertilizers, Proceedings of a project (SMCN/2002/073) workshop held in Hanoi, Vietnam. Kenedyetal, I. R. (Ed.), 126130.

Seneviratne, G., J. S. Zavahir, W. M. M. S. Bandara and M. L. M. A. W. Weerasekara (2008b). "Fungal-bacterial biofilms: Their development for novel biotechnological applications". World J. Microbiol. Biotechnol. 24: 739-743.

Seneviratne, G., A. P. D. A. Jayasekara, M. D. L. De Silva and U. P. Abeysekara (2011). "Developed microbial biofilms can restore deteriorated conventional agricultural soils". J. Soil Biology and Biochemistry. 43: 1059-1062.

Seneviratne, G., R. M. M. S. Thilakaratne, A. P. D. P. Jayasekara, K. A. C. N. Seneviratne, K. R. E. Padmathilake and M. S. D. L. De Silva (2009). "Developing beneficial microbials on root of nonlegumes: A novel biofertilizing technique". In: Microbial strategies for crop improvement. Khanetal, M. S. (Ed.). Springer - Verlag, Berlin, Heidelberg. 51-62.

Wastie, R. L. (1965). "The occurrence of an Endogoone type of endotrophicmycorrhiza in Hevea brasiliensis". Transactions of the British Mycological Society. 48: 167-168.

Young, K. D. (2007). "Bacterial morphology: why have different shapes?" Curr Opin Microbiol. 10(6): 596-600. 